\title{
Atmospheric Blocking and Atlantic Multi-decadal Ocean Variability
}

\section{Sirpa Häkkinen ${ }^{1}$, Peter B. Rhines ${ }^{2}$ and Denise L. Worthen ${ }^{3}$}

${ }^{1}$ NASA Goddard Space Flight Center, Code 614.1, Greenbelt, MD 20771

2 Univ. of Washington, Box 357940, Seattle, WA 98195

${ }^{3}$ WYLE ITS Systems/NASA Goddard Space Flight Center, Code 614.1, Greenbelt, MD 20771

Corresponding author e-mail: sirpa.hakkinen@nasa.gov

Brief summary:

Based on the $20^{\text {th }}$ century atmospheric reanalysis, winters with more frequent blocking, in a band of blocked latitudes from Greenland to British Isles, are found to persist over several decades and correspond to a warm North Atlantic Ocean, in-phase with Atlantic multi-decadal ocean variability. 


\begin{abstract}
Atmospheric blocking over the northern North Atlantic involves isolation of large regions of air from the westerly circulation for 5-14 days or more. From a recent $20^{\text {th }}$ century atmospheric reanalysis $(1,2)$ winters with more frequent blocking persist over several decades and correspond to a warm North Atlantic Ocean, in-phase with Atlantic multi-decadal ocean variability (AMV). Ocean circulation is forced by wind-stress curl and related air/sea heat exchange, and we find that their space-time structure is associated with dominant blocking patterns: weaker ocean gyres and weaker heat exchange contribute to the warm phase of AMV. Increased blocking activity extending from Greenland to British Isles is evident when winter blocking days of the cold years (1900-1929) are subtracted from those of the warm years (19391968).
\end{abstract}


Introduction

The North Atlantic Oscillation (NAO) is the dominant atmospheric mode of variability over the Atlantic with maximum values of the $20^{\text {th }}$ century in the early 1990 s, a reversal in 1995/1996 winter and a return to moderately weak positive and negative fluctuations since then. Particularly, the NAO index does not exhibit any unusual changes in the transition from the late 1990s to the 2000s which could impact the upper ocean circulation. However, a major shift in the North Atlantic surface currents as measured by surface drifter paths has occurred recently where branches of the North Atlantic Current veered north-eastward after 2001 (beginning in mid-1990s and intensifying after 2001) from their preferential path towards the south-east (as observed since the beginning of the drifter program in 1989) (3). This change in the surface currents, bringing more warm and saline waters from subtropics has significantly contributed to increased salinity in the subpolar gyre and in the waters flowing to the Nordic Seas (4).

The subpolar Atlantic salinity (and temperature) fluctuations have a multi-decadal character such that similar high salinity (and warm) conditions dominated from the 1920s to the 1960s (with some interannual fluctuations); fresher (and cold) conditions dominated from 1970s to the 1990s (5). Based on the 50-year reanalysis (1958-2007) of ocean hydrographic data (Simple Ocean Data Assimilation (SODA) data set (6)), high salinity events are associated with an increased transport of the most saline component (over $35.3 \mathrm{psu}$ ) of the North Atlantic Current (7). The atmosphere drives ocean circulation through both heat and moisture exchange and winds; the curl of the wind-stress in particular causes downward or upward pumping of waters which energize the circulation gyres. Analysis of the wind stress curl showed that the bursts of the most saline transport were associated with atmospheric regimes having a curl anomaly, which opposes the climatological curl field, i.e. when the wind-driven gyre component 
is weak. And indeed, the long decline of subpolar gyre surface currents from 1994 to 2000 revealed by satellite altimetry $(8)$ correspond with a weakening wind-curl field. Impacts on marine ecosystems of this ocean circulation variability mode, based on fish-catch and pilotwhale observations carrying back over several centuries, have been documented (9).

Likely the most dramatic climate event of the $20^{\text {th }}$ Century, the pre-greenhouse-gas northern warming that began in the 1920s and lasted through the 1960s, is a part of an irregular cycling known as Atlantic Multidecadal Variability (AMV, or Atlantic Multi-decadal Oscillation, AMO), The AMV/AMO is apparent in the subpolar gyre and also dominates the entire North Atlantic Ocean sea surface temperature (SST) variability $(10,11)$. This SST mode has been considered to be an important modulator for the Atlantic hurricane activity (11). AMO can be linked to many other multi-decadal climate impacts, e.g. NE Brazil and Sahel rainfall, North American and European summer climate (12). Hydrographic data analysis also shows that the subsurface temperature variability contains a signal of the multi-decadal mode with an opposite tendency between the upper and deeper ocean (13).

Relationship between the NAO index and the atmospheric regime with enhanced saline (subtropical) water intrusions to the northernmost latitudes is not firmly tied to the negative phase of NAO. Using another technique to classify atmospheric regimes such as cluster analysis (e.g. 14 and 15 and references therein) one can uncover a set of four clusters where NAO negative and NAO positive emerge as separate clusters along with 'Atlantic Ridge' and 'Blocking' clusters. The Atlantic Ridge cluster, a single center of variability in the subpolar gyre south of Iceland, has been very active since year 2000 (15). The cluster analysis highlights the asymmetry of the NAO negative and NAO positive regimes such that sea level pressure (SLP) centers are not co-located. This asymmetry between negative and positive NAO states can be 
especially obvious at the upper level winds (i.e. in the jet stream): If $300 \mathrm{hPa}$ winds are composited against the daily NAO index (from e.g. Empirical Orthogonal Function (EOF) based SLP analysis), a SW to NW subpolar jet separated from the subtropical jet exists in NAO positive periods and a single continuous subtropical jet crossing the Atlantic exists during the negative NAO periods (Figure 1 in (16)). In the negative NAO case the upper level winds form an anticyclonic pattern over the subpolar ocean. At extremes, this high-pressure pattern can block the westerlies over the subpolar ocean, hence these events are called Greenland blocking episodes. They have long been known to be accompanied with unusually cold winter temperatures in Europe (17). Particularly cold winters of 1963 and 2009/2010 in the western Europe have been associated with blocking (18). North Atlantic blocking represents an extreme state of the eddy-driven jet stream, with large-amplitude waves at the dynamical tropopause level distorting, 'breaking' and impeding the normal westerly circulation by locating high-pressure anticyclones in their path (19). (An example of Atlantic blocking is given in Figure S1.)

Blocking is not limited to the region surrounding the southern Greenland, but the blocking events are also very frequent in a band crossing over from Greenland to the British Isles with a climatological maximum of winter blocking days over the British Isles if one uses an absolute geopotential height index of (20) (figure 2a in (21); also the long term average blocking days from the 20th century reanalysis shown in Figure S2). Similar emphasis on the peak of blocking days over Europe appears in a tropopause/potential temperature based index (22). Blocking over the western Europe occurs typically during a positive NAO phase (21).

In the following we will show that the winters with high number of blocking days are most likely to result in the wind stress curl pattern which we found to be common during the saline episodes of the 1960s, late 1970s (weak event) and early 2000s (7). We will show that the 
changes of blocking days also appear to be linked to AMV so that the decades with more blocking days are associated with positive SST anomalies over the North Atlantic. While blocking near Greenland has been associated with the negative NAO index (e.g., (19)), the particularly strong episode of subpolar warming in the early 2000s was not associated with strongly negative NAO, but with increased blocking activity from Greenland to western Europe leading to weakening of wind-stress curl and decreased heat loss over the subpolar Atlantic.

Data

The data sources for our study are the wind stress, $500 \mathrm{hPa}$ heights, sensible and latent heat flux and SLP data from National Center for Environmental Prediction and National Center for Atmospheric Research (NCEP/NCAR) Reanalysis 1951-onwards, and from a $20^{\text {th }}$ Century Reanalysis $(1,2)$ for $1900-2008$. The wind stress curl is a derived product compiled to December to March averages. We also computed the number of blocking days in December to March time frame from the daily $500 \mathrm{hPa}$ height data. All analyses are performed with the $20^{\text {th }}$ century data, except for comparisons made with modern NCEP/NCAR reanalysis data.

We use the Hadley Center sea surface temperature (SST) from 1901 onwards for linkages to Atlantic Multi-decadal Oscillation. The years 1925-1970 and 1971-1995 constitute the warm and cold phase of the Atlantic Multi-decadal Oscillation (10). Other definitions of cold and warm years also have been used in the literature, such as 1900-1929 and 1939-1968 (23), which are adopted here for the cold and warm period. 
Climate regimes defined by wind-stress curl

Storms, through their frequency, track-line and strength are imprinted in the wind stress, which forces the ocean through its vorticity (curl) and Ekman transport. The wind stress curl variability acts as a critical forcing for changes in the ocean gyre circulation, hence indices for its variability could be used to classify climate regimes important for ocean climate. To create indices of climate variability we choose the EOF analysis of the winter (December through March) wind stress curl for the full $20^{\text {th }}$ century reanalysis (and for the 60-year NCEP/NCAR Reanalysis for comparison). Both datasets give essentially the same EOF patterns and amplitudes. EOF1 (Figure 1a, top) has a center west of the British Isles and its time series (principal component, PC, in Figure 1b) correlates highly with the NAO index. It has a center of action straddling the boundary between subpolar and subtropical gyres. EOF2 shown for the $20^{\text {th }}$ century analysis (Figure 1a, bottom) displays maximum amplitude of activity located over the ocean gyres and its time series, PC2, is shown Figure $1 \mathrm{~b}$. The $2^{\text {nd }}$ mode represents the modulation of climatological pattern and hence the strength of the gyre circulation.

NCEP/NCAR and $20^{\text {th }}$ century reanalysis data sets give almost identical time series for the latter half of the century.

For the recent decades, 1960-2005, the PC2 timeseries of the wind stress curl was found to be the key index associated with the saline and warm periods in the northern North Atlantic Ocean because it controls the expansion/contraction and strength of both subpolar and subtropical gyres (7). With a longer atmospheric reanalysis we can now address climate regimes associated with the SST variability such as the AMV. Our focus is on the wind stress curl PC2 of the EOF analysis, but PC1 is invoked to distinguish the regime associated with curl EOF2 
from NAO associated variability. We primarily form composites of various quantities in the atmospheric reanalysis corresponding to negative and positive events in curl PC2 (and/or PC1) exceeding one standard deviation to highlight the North Atlantic climate regimes. All analysis results displayed, excepting Figure 2 , are computed solely using the $20^{\text {th }}$ century reanalysis data.

Decadal variability of the blocking days

The number of wintertime blocking days (from December to March) was determined from the daily $500 \mathrm{hPa}$ height data. We used the definition (20) based on north-south dynamic height gradient at $500 \mathrm{hPa}$ over the latitude range $30 \mathrm{~N}-75 \mathrm{~N}$ at each longitude and requiring persistence of at least 5 days. Blocking indices based on reversals of the meridional gradient of potential temperature at the tropopause have refined the description of blocking modes, yet they yield a similar picture to the (20) index in our region of interest (20). We further summed these blocking days into decadal fields shown in Figure 2a. The shown decadal fields up to 1950 are from the $20^{\text {th }}$ century reanalysis and after 1951 the blocking days are from NCEP/NCAR Reanalysis. The $20^{\text {th }}$ century reanalysis tends to overestimate blocking days compared with the NCEP/NCAR in the overlapping period (Figure S3). However, it is obvious that some decades display more prominently blocking activity than others. Especially, when the blocking is active over the British Isles and has an extension towards Greenland, the warmest periods occur in the North Atlantic Ocean, i.e., 1920-1970, and after 2000. This association is evident in Figure 2b showing the time series of blocked days in a region $\left(45^{\circ} \mathrm{N}-65^{\circ} \mathrm{N}, 10^{\circ} \mathrm{E}-70^{\circ} \mathrm{W}\right)$ and $\mathrm{AMO}-\mathrm{index}$ which is the area averaged SST over the North Atlantic region $0^{\circ} \mathrm{N}-65^{\circ} \mathrm{N}, 10^{\circ} \mathrm{E}-80^{\circ} \mathrm{W}$. 
Relationship between wind stress curl and sea level pressure (SLP); blocking signature

Sea-level pressure (SLP) is often used to characterize decadal climate variability. Here we compare SLP with the field of primary interest for ocean circulation, the wind-stress curl. The wind stress curl EOF2 mode acts as a modulation of the climatological pattern that creates the gyres. Hence we can call its timeseries PC2 the 'gyre mode index'. Wind-stress curl relates to the vorticity of the winds, hence to the Laplacian of SLP which exhibits smaller-scale features. The relationship of the gyre index to the leading SLP mode, NAO, is unclear, so we form an SLP composite corresponding to negative minus positive curl PC2 events. The resulting pattern (Figure 3a) resembles the NAO SLP pattern but the center of activity has shifted south and west. It is similar to the Eastern Atlantic pattern in SLP EOF analysis $(21,24)$, and also to the Atlantic Ridge pattern found with cluster analysis $(14,15)$. The Eastern Atlantic SLP pattern has been identified as a blocking signature (21). This same SLP pattern, although only the southern center between 30N-40N, was recovered as a difference of warm years 1939-1968 minus cold years of 1900-1929 (23). With a slightly different binning of the warm (1950-1964) and cold (19701984) years the SLP pattern resembles more the negative NAO pressure anomaly (25). The (lagged) time series associated with the multi decadal AMV temperature mode is also linked to the Eastern Atlantic SLP pattern (13), but lagged by 11 years with the NAO index. While there is no spatial correlation between the NAO pattern and the wind curl EOF2, and the PC2 is not strongly correlated with the NAO index, the PC2 time series shows remarkably close relationship with the subpolar SLP anomaly (Figure 3b) and, less significantly, with the subtropical Azores SLP center. Observationally the relationship between the low frequency Azores SLP and ocean gyre variability arises from analysis of the sea level variability along the European coast (26). 
Relationships between blocking, wind stress curl, heat flux and AMV

To establish the linkage between the wind stress curl variability and blocking we form composites using the two wind-stress curl modes PC1 and PC2 as indices with particular attention to the multi-year and multi-decade time scales. First the blocking activity corresponding to PC1 (Figure 4a, as negative minus positive PC1 events) shows the Greenland blocking activity known to be associated with the negative phase NAO (16). On the other hand, the PC2 composites (again as negative minus positive PC2 events, Figure 4b) show simultaneous activity of the western European blocking and Greenland blocking, flanked by decreased blocking over Scandinavia and Southern Europe. This is in striking contrast to a simple association of Greenland blocking to the negative NAO index. This specific blocking anomaly reaching from Greenland to western Europe represents fluctuations of the basic climatologicalmean blocking pattern (Figure S2) with contributions also from positive NAO index. These NAO-positive contributions occur over the eastern side of the North Atlantic and western Europe.

The active blocking band from Greenland to the western Europe was also seen in decadal variability of the extended early-midcentury warm period (Figure 2). In fact using the AMO index (with no detrending; Figure 2b) to form a composite (positive minus negative) of the blocking events (Figure 4c) gives the same active band of blocking as the wind stress curl PC2 although with less areas of significance. If we use the same years as in (23) to define warm period (1939-1968) and cold period (1900-1929), the resulting difference in blocking days (Figure 4d) has a pattern very similar to that corresponding to the curl PC2. The areas of significance of $95 \%$ or higher are stippled assuming maximum 58 degrees of freedom. 
In addition to the association of warm, saline ocean with weakening of the wind-stress curl and the subpolar and subtropical gyre circulation, air-sea heat flux is a factor. The composite of turbulent (sensible and latent) heat flux corresponding to (negative minus positive) curl PC2 (Figure 5) shows the heat flux anomaly associated with the climate regimes which have weak circulation gyres and high blocking activity. This heat flux anomaly favors heating in large part of the North Atlantic including the Equatorial region with weak cooling in a narrow band in the mid-latitudes where the subtropical jet crosses the Atlantic. This heating anomaly pattern differs from that corresponding to the NAO index, where the subpolar heating/cooling is centered over the Labrador Sea (instead of the central subpolar gyre) and the cooling/heating over the Gulf Stream region is of the same order of magnitude as in the Labrador Sea.

Figures 4 show that a similar blocking activity can be recovered whether using the gyre index (wind stress curl PC2) or multidecadal SST variability as the compositing index. This is an implication that the particular blocking anomaly is fundamental part of the forcing of the gyre variability at low frequencies. Moreover it is associated with surface heat exchange which supports heat content variability (Figure 5), in turn amplifying the effects of expanding and contracting gyres.

Summary

Variability of atmospheric blocking over years to several decades shows correlation with the ocean surface temperature and with significant changes in ocean circulation, mediated by wind-stress curl and air-sea heat exchange. The wind stress curl variability of most importance for the North Atlantic gyre circulation represents amplitude modulation of the climatological curl pattern. This same mode of variability is associated with a major shift in the upper ocean currents 
after year 2000. However the time series of the amplitude modulation has a weak relationship with NAO which itself projects on a different curl pattern with a center of variability west of the British Isles between the subtropical and subpolar gyres. This motivated the search for other features in the atmospheric forcing related to wind stress curl variability. With the $20^{\text {th }}$ century reanalysis $(1,2)$ we could also address the atmospheric conditions associated with the multidecadal (AMO/AMV) warming of the North Atlantic Ocean in mid-century.

Since the wind stress curl variability represents changes in the Atlantic storm track, storm frequency and intensity, we focused on persistent, i.e. blocking, events where storm tracks are shifted. For example with negative NAO index a block over southern Greenland forces the existence of single upper level mid-latitude jet crossing the Atlantic. However our wind stress curl pattern of interest, the gyre mode, is not projecting purely on the Greenland blocking but contains an even more important component of the western European block centered on the British Isles. Hence we conclude that the modulation of the climatological curl pattern is created by the changes in the climatological blocking pattern consisting of blocked latitudes from both Greenland and western Europe. Increased activity of both, Greenland and western Europe, blocking centers has occurred when the North Atlantic has been in a warm state. PC2 affects gyre circulation, allowing increased northward penetration of warm subtropical waters during years of high blocking activity. The same wind-stress curl mode also supports atmosphere-ocean heat exchange which sustains a warm state of the North Atlantic, from the subpolar region through most of the subtropics to the Equator.

The blocking events (lasting 5days - 14days or more) provide on example of high frequency atmospheric variability projecting on lower frequency variability of the wind stress curl. Winters with more blocking days appear to persist for decades. Our analysis cannot 
separate cause and effect between high blocking activity and warm ocean surface but the existing theory of the mid-latitude atmosphere-ocean interaction supports increased persistence of atmospheric anomalies that created oceanic anomalies in the first place (27). The possibility of coupled interaction of atmosphere (with Atlantic Multi-decadal Variability and at shorter timescale) seems likely, given the long-period variability of blocking reported here, and in the even longer paleo-climate time series (28). The relation between the climatically important Atlantic Meridional Overturning Circulation (AMOC) and AMV variability has not been established but AMV exhibits also vertical structure which could signal AMOC variability (13). Internal oscillation modes of ocean overturning circulation, $\operatorname{AMOC}(29,30)$, may have been active in weakening the subpolar gyre circulation in the mid-1990s. The idea is that the strong atmospheric forcing immediately prior to 1995 strengthened the AMOC, bringing warm subtropical waters northward, which then fed back negatively, initiating the weakening observed later in the decade. Clearly, the possibility of phase-lagged feedbacks like this, reaching out to the hemispheric jet-stream waveguide, to tropical ocean temperatures and to the AMOC itself, have to be acknowledged. Our zero-phase-lag discussion is one step in that direction, associating atmospheric blocking and weakened wind-stress curl with weakened ocean gyres and increased penetration of warm Atlantic subtropical waters poleward, 


\section{References:}

1. G. P. Compo, J.S. Whitaker, and P.D. Sardeshmukh, Feasibility of a 100 year reanalysis using only surface pressure data. Bull. Amer. Met. Soc., 87, 175-190, (2006).

2. G. P. Compo, et al., The Twentieth Century Reanalysis Project. Q. J. R. Meteorol. Soc., 137, $1-28(2011)$.

3. S. Häkkinen, and. P.B. Rhines, Shifting surface currents of the northern North Atlantic Ocean. J. Geophys. Res., 114, doi:10.1029/2008JC004883 (2009).

4. N. P. Holliday et al., Reversal of the 1960s-1990s freshening trend in the north-east North Atlantic and Nordic Seas. Geophys. Res. Lett., 35, L03614, doi:10.1029/2007GL032675 (2008).

5. G. Reverdin, North Atlantic subpolar gyre surface variability (1895-2009). J. Clim., 23, 4571-4584 (2010).

6. J. A. Carton, and B.S. Giese, A reanalysis of ocean climate using Simple Ocean Data Assimilation (SODA). Mon. Wea. Rev., 136, 2999-317 (2008).

7. S. Häkkinen, P.B. Rhines and D.L. Worthen, Warm and saline events embedded in the meridional circulation of the northern North Atlantic. J. Geophys. Res., 116, C03006, doi:10.1029/2010JC006275 (2011).

8. S. Häkkinen, and Rhines, Decline of subpolar North Atlantic gyre circulation during the 1990s. Science, 304, 555-559 (2004).

9. H. Hătún, et al., Large bio-geographical shifts in the north-eastern Atlantic Ocean: From the subpolar gyre, via plankton, to blue whiting and pilot whales. Prog. in Oceanogr. 80, 149-162 (2009). 
10. D. B. Enfield, A.M. Mestaz-Nunez, and P.J. Trimble, The Atlantic multi-decadal oscillation and its relation to rainfall and river flows in the Continental US. Geophys. Res. Lett., 28, 20772080 (2001).

11. K. E. Trenberth, and D.J. Shea, Atlantic hurricanes and natural variability in 2005. Geophys. Res. Lett., 33, L12704, doi:10.10129/2006GL026894 (2006).

12. J. R. Knight, C. K. Folland, and A. A. Scaife, Climate impacts of the Atlantic Multi-decadal Oscillation. Geophys. Res. Lett., 33, L17706, doi:10.1029/2006GL026242 (2006).

13. I. V. Polyakov, V.A. Alexeev, U.S. Bhatt, E.I. Polyakova and X. Zhang, North Atlantic warming: patterns of long-term trend and multidecadal variability. Clin. Dyn., 34, 439-457 (2010).

14. C. Cassou, L. Terray, J.W. Hurrell and C. Deser, North Atlantic winter climate regimes: spatial symmetry, stationarity with time and oceanic forcing. J. Clim., 17, 1055-1068 (2004).

15. J. W. Hurrell, and C. Deser, North Atlantic climate variability: The role of the North Atlantic Oscillation. J. Mar. Syst., 79, 231-244 (2010).

16. T. Woollings, A. Hannach, B. Hoskins, and A. Turner, A regime view of the North Atlantic Oscillation and its response to anthropogenic forcing. J. Clim., 23, 1291-1307 (2010).

17. D. F. Rex, Blocking action in the middle troposphere and its effect upon regional climate. Tellus, 2, 196-211 (1950).

18. J. Cattiaux et al., Winter 2010 in Europe: A cold extreme in a warming climate. Geophys. Res. Lett., 37, L20704, doi:10.1029/2010GL044613 (2010).

19. T. Woollings, B. J. Hoskins, M. Blackburn and P. Berrisford, A new Rossby-wave breaking interpretation of the North Atlantic Oscillation. J. Atmos. Sci. 65, 609-626 (2008). 
20. S. Tibaldi, and F. Molteni, On the operational predictability of blocking. Tellus, 42A, 343365 (1990).

21. S. C. Scherrer, M. Croci-Maspoli, C. Schwierz and C. Appenzeller, Two-dimensional indices of atmospheric blocking and their statistical relationship with winter climate patterns in the Euro-Atlantic region. Int. J. Climatol., 26, 233-249 (2006).

22. E. Tyrlis, and B.J. Hoskins, Aspects of a Northern Hemisphere blocking climatology. J. Atm. Sci., 65, 1638-1652 (2008).

23. C. Deser and M.L. Blackmon, Surface climate variations over the North Atlantic Ocean during winter: 1900-1989. J. Clim., 6, 1743-1753 (1993).

24. M. Croci-Maspoli, C. Schwierz, and H.C. Davies, Atmospheric blocking: space-time links to NAO and PNA. Clim. Dyn., 29, 713-725 (2007).

25. Y. Kushnir, Interdecadal variations in North Atlantic sea surface temperature and associated atmospheric conditions. J. Clim., 7, 141-157 (1994).

26. L. Miller, and B.C. Douglas, Gyre-scale atmospheric pressure variations and their relation to $19^{\text {th }}$ and $20^{\text {th }}$ century sea level rise. Geophys. Res. Lett., 34, L16602, doi:

10.1029/2007GL030862 (2007).

27. J. J. Barsugli, and D.S. Battisti, The basic effects of atmosphere-ocean thermal coupling on midlatitude variability. J. Atm. Sci., 55, 477-493 (1998).

28. E. Rimbu, and G. Lohmann, Winter and summer blocking variability in the North Atlantic region - evidence from long-term observational and proxy data from southwestern Greenland.

Clim. Past Disc. 5, 2411-2437 (2009).

29. S. Häkkinen, Decadal air-sea interaction in the North Atlantic based on observations and modeling results. J. Clim., 13, 1195-1219 (2000). 
30. K. Lohmann, H. Drange and M. Bentsen, A possible mechanism for the weakening of the North Atlantic subpolar gyre in the mid-1990s. Geophys. Res. Lett. 36, doi:

10.1029/2009GL039166 (2009).

\section{Acknowledgements}

SH and DLW were funded by NASA Headquarters Physical Oceanography Program and OSTM Science Team. PBR is supported by NASA through the OSTM Science Team.

The data used in this study are retrieved from the following public sites:

The 20th Century Reanalysis:

http://www.esrl.noaa.gov/psd/data/gridded/data.20thC_ReanV2.html

NCEP/NCAR Reanalysis:

http://www.esrl.noaa.gov/psd/data/gridded/data.ncep.reanalysis.html

Hadley SST (HadISST = Hadley sea ice and sea surface temperature):

http://www.hadobs.org/

\section{Figure Captions}

Figure 1. The wind stress curl variability based on EOF analysis.

(a) spatial pattern of wind stress curl EOFs from the $20^{\text {th }}$ century atmospheric reanalysis $(1,2)$.

EOF1 (top) represents $22.3 \%$ of the wind stress curl variability, and has its centers of 
action displaced north-south relative to the subpolar ocean gyre. EOF2 (bottom panel) with $15.6 \%$ of the variance has centers of action coinciding with the subpolar and northern subtropical ocean gyres.

(b) Principal components of wind stress curl EOFs from the $20^{\text {th }}$ century reanalysis. PC1 (red), PC2 (blue), and from NCEP/NCAR Reanalysis PC1(dashed black), and PC2 (dashed purple). Time series are smoothed by 10 binomial filters.

Figure 2. (a) Blocking days by decade. Composite of $1901-1950$ from the $20^{\text {th }}$ century reanalysis, and 1951-2010 from NCEP/NCAR Reanalysis. (b) DJFM Blocking days in the region $10^{\circ} \mathrm{E}-70^{\circ} \mathrm{E}, 45^{\circ} \mathrm{N}-75^{\circ} \mathrm{N}$ from the $20^{\text {th }}$ century reanalysis (red curve) and from NCEP/NCAR Reanalysis (purple curve). The AMO-index (black curve)is an area-averaged SST from $0^{\circ} \mathrm{N}-65^{\circ} \mathrm{N}, 10^{\circ} \mathrm{E}-80^{\circ} \mathrm{W}$.

Figure 3. Relationship between the gyre index and SLP.

(a) Composite of SLP based on negative minus positive curl PC2 events stronger than one standard deviation. Stippling denotes significance of difference at $95 \%$ level.

(b) Subpolar SLP (black) (average over 20W-50W, 50N-65N) and curl PC2 (blue) from the $20^{\text {th }}$ century reanalysis smoothed by 20 binomial filters.

Figure 4. Anomaly patterns of blocking activity.

(a) Composite of blocking days based on negative minus positive curl PC1 events stronger than one standard deviation. Stippling denotes significance of difference at 95\% level.

(b) Composite of blocking days based on negative minus positive curl PC2 events stronger than one standard deviation. Stippling denotes significance of difference at 95\% level.

(c) Composite of blocking days based on positive minus negative AMO events stronger than one standard deviation. Stippling denotes significance of difference at $95 \%$ level. 
(d) Warm minus cold years (1939-1964 minus 1900-1929 as defined in (21)) difference in blocking days. Stippling denotes significance of difference at 95\% level assuming 58 degrees of freedom.

Figure 5. Anomaly of the surface heat exchange associated with the gyre index. Composite of turbulent heat flux (positive upward) based on negative minus positive curl PC2 events stronger than one standard deviation. Stippling denotes significance of difference at $95 \%$ level.

Figure S1. Example of Atlantic blocking from NCEP analysis. 500hPa geopotential height (contours; $\mathrm{m})$, and its anomalies (color; $\mathrm{m})$. From

http://www.cpc.ncep.noaa.gov/products/precip/CWlink/blocking/background/atlantic_case.shtml Figure S2. Climatological number of blocking days in December-March season.

Figure S3 . Decadal blocking days from the $20^{\text {th }}$ century reanalysis. 


\section{Figures}
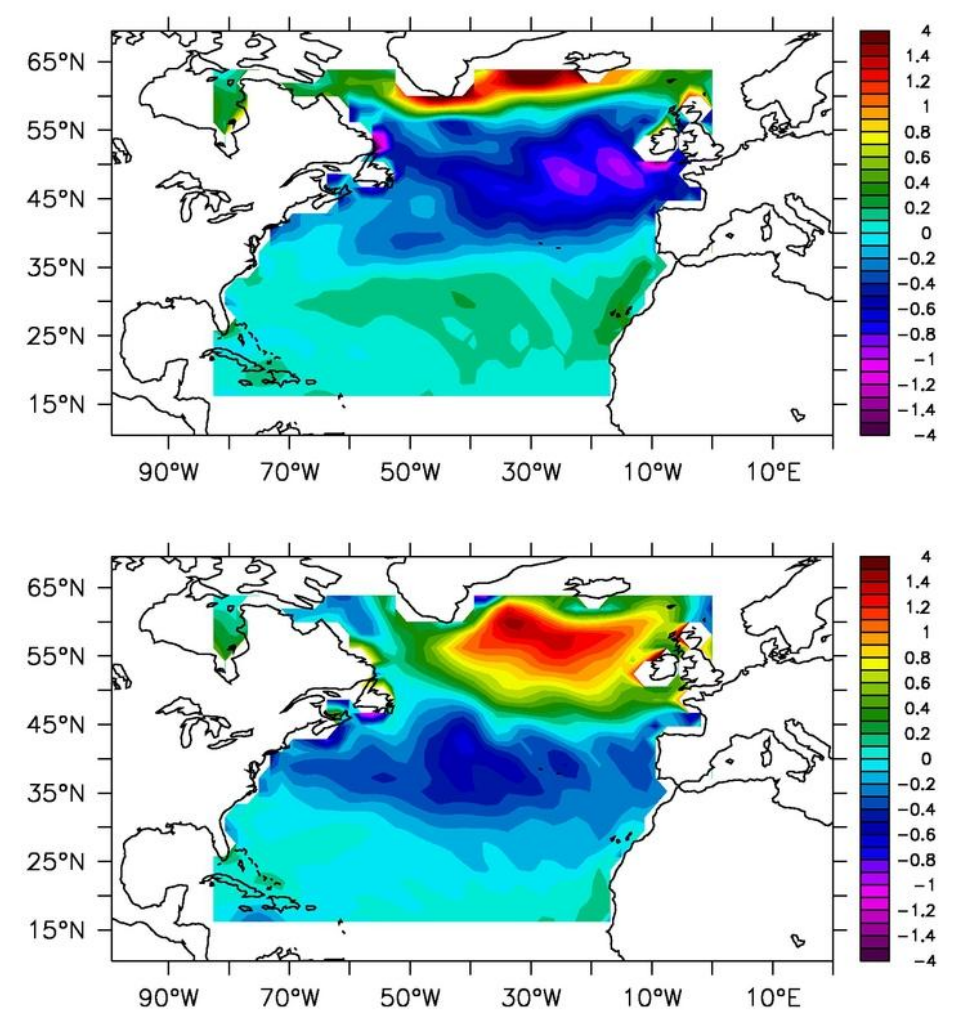

Figure 1 (a) spatial pattern of wind stress curl EOFs from the $20^{\text {th }}$ century atmospheric reanalysis $(1,2)$. EOF1 (top) represents $22.3 \%$ of the wind stress curl variability, and has its centers of action displaced north-south relative to the subpolar ocean gyre. EOF2 (bottom panel) with $15.6 \%$ of the variance has centers of action coinciding with the subpolar and northern subtropical ocean gyres. 


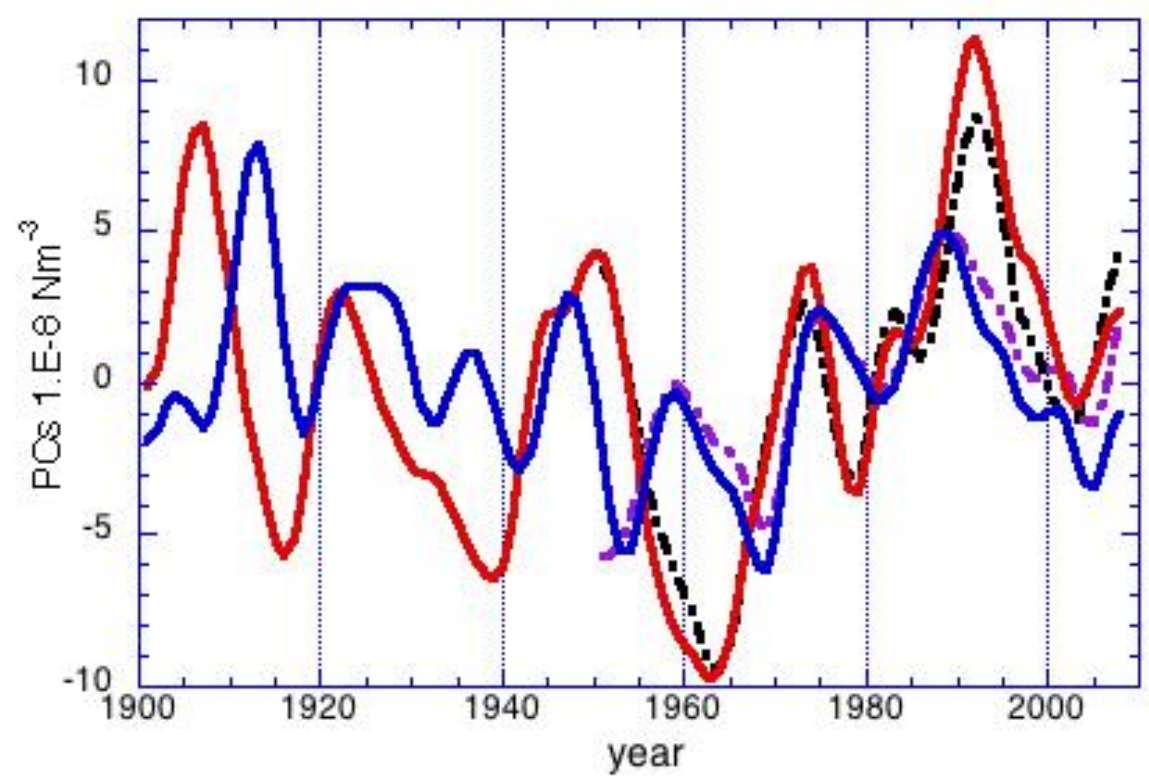

Figure 1(b) Principal components of wind stress curl EOFs from the $20^{\text {th }}$ century reanalysis. PC1 (red), PC2 (blue), and from NCEP/NCAR Reanalysis PC1(dashed black), and PC2 (dashed purple). Time series are smoothed by 11-point binomial filter. 

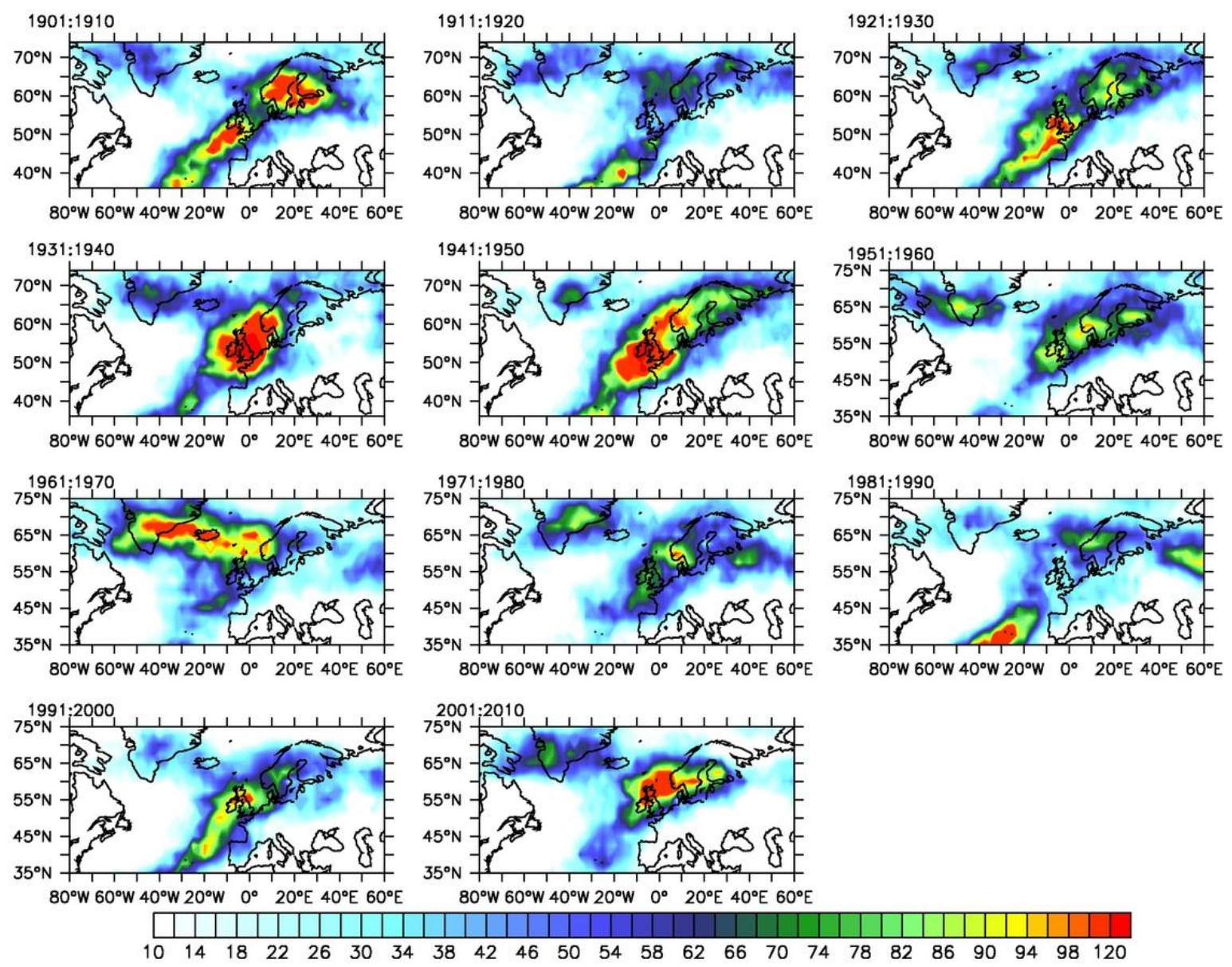

Fig 2a. Blocking days by decade: $1901-1950$ from the $20^{\text {th }}$ century reanalysis, $1951-2010$ from NCEP/NCAR Reanalysis. 


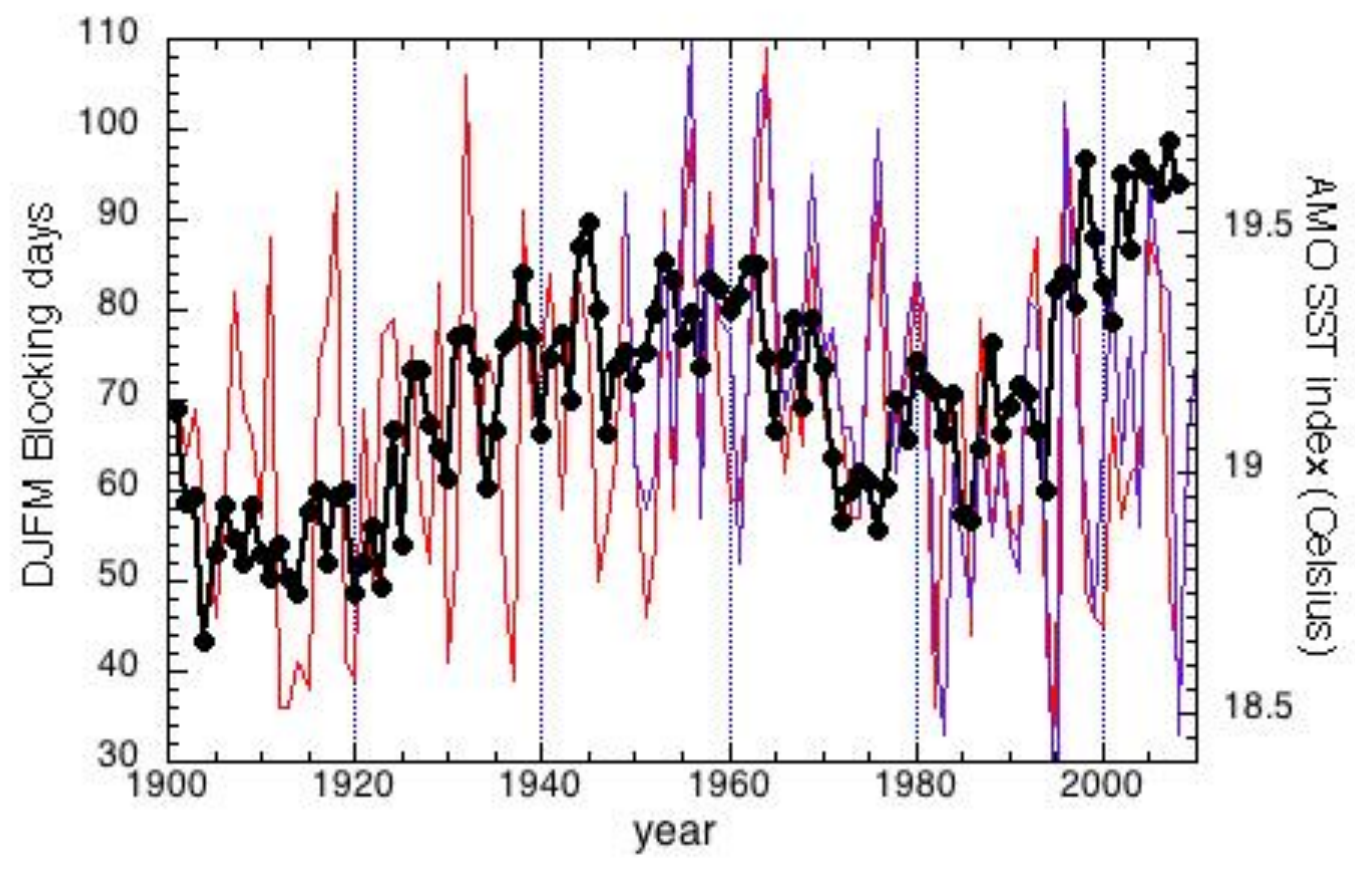

Figure $2 \mathrm{~b}$ DJFM Blocking days in the region $10^{\circ} \mathrm{E}-70^{\circ} \mathrm{E}, 45^{\circ} \mathrm{N}-75^{\circ} \mathrm{N}$ from the $20^{\text {th }}$ century reanalysis (red curve) and from NCEP/NCAR Reanalysis (purple curve). The AMO-index (black curve) is an area averaged SST from $0^{\circ} \mathrm{N}-65^{\circ} \mathrm{N}, 10^{\circ} \mathrm{E}-80^{\circ} \mathrm{W}$. 


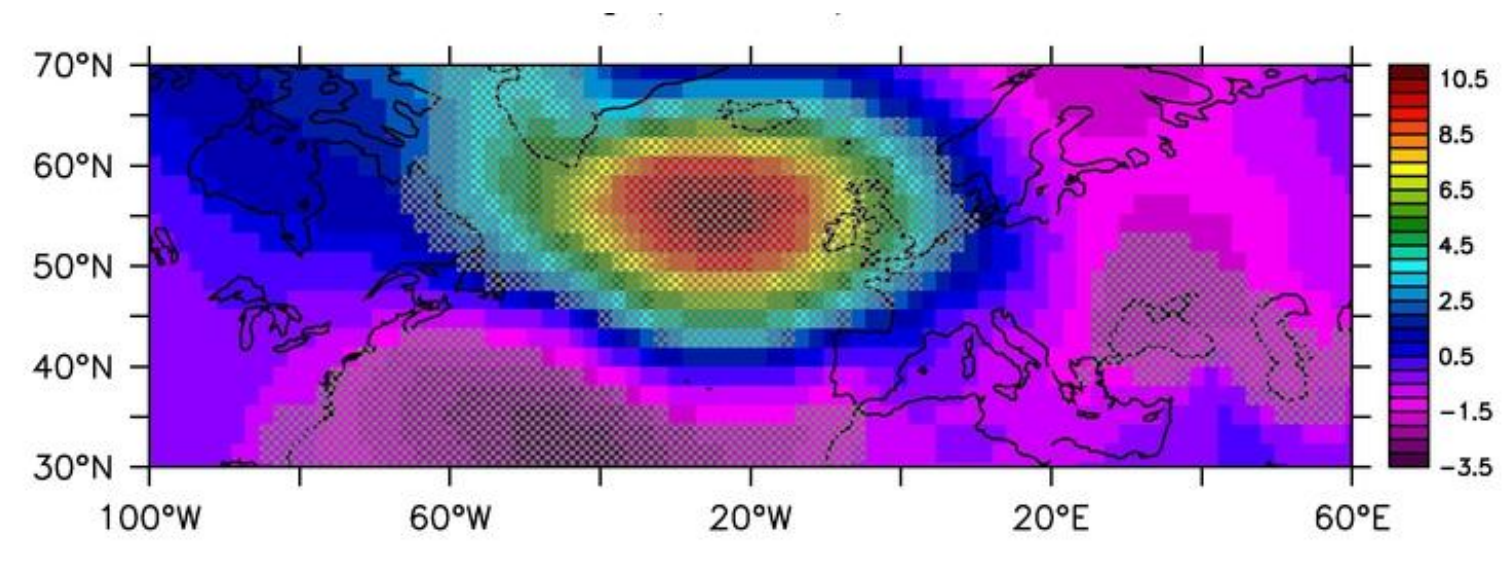

Fig 3a Composite of SLP based on negative minus positive curl PC2 events stronger than one standard deviation. Stippling denotes significance of difference at 95\% level.

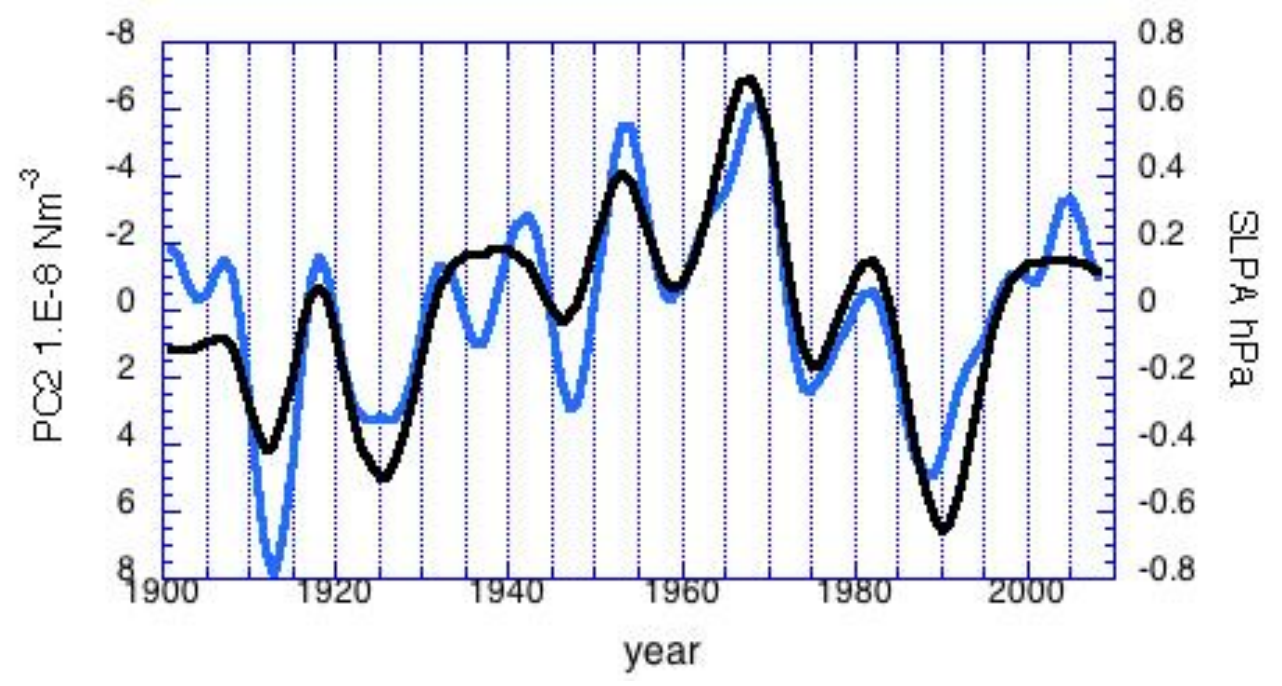

Fig 3b Subpolar SLP (black) (average over 20W-50W, 50N-65N) and curl PC2 (blue) from the $20^{\text {th }}$ century reanalysis smoothed by 21 -point binomial filters. 


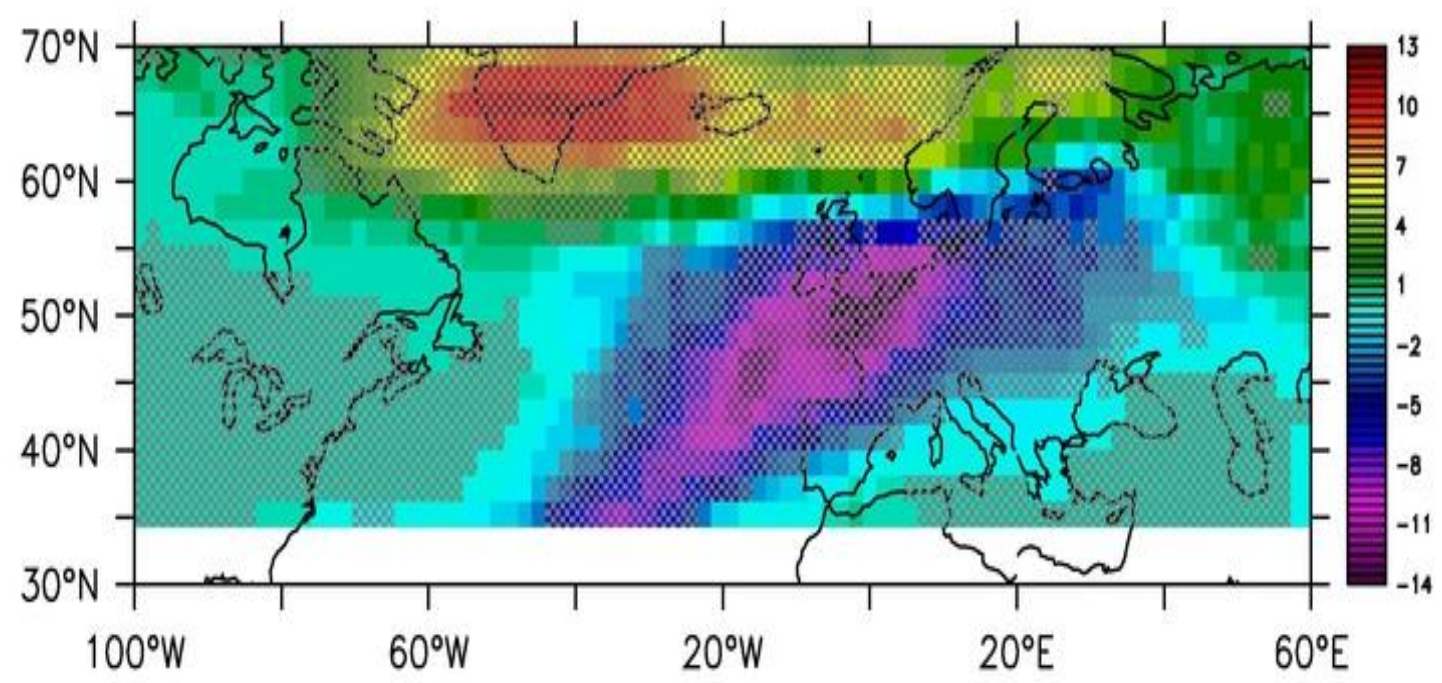

Figure 4a Composite of blocking days based on negative minus positive curl PC1 events stronger than one standard deviation. Stippling denotes significance of difference at $95 \%$ level.

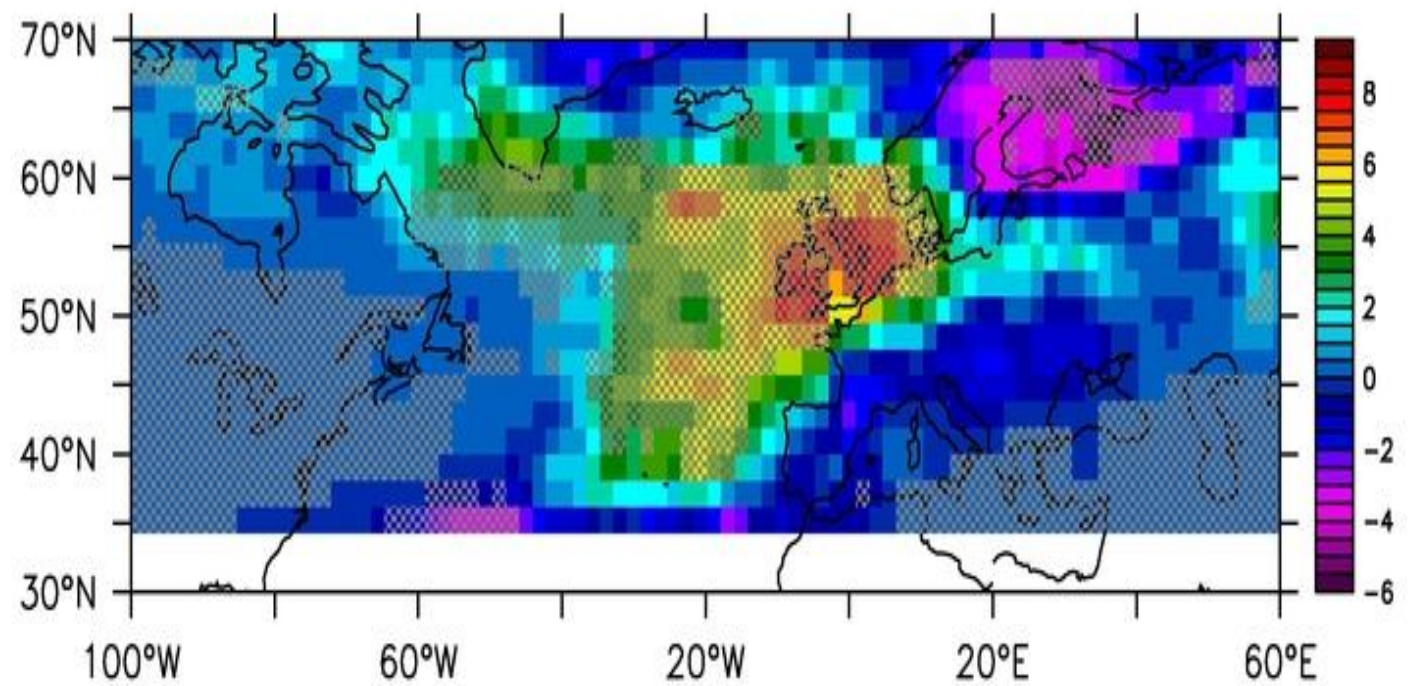

Figure $4 \mathrm{~b}$ Composite of blocking days based on negative minus positive curl PC2 events stronger than one standard deviation. Stippling denotes significance of difference at $95 \%$ level. 


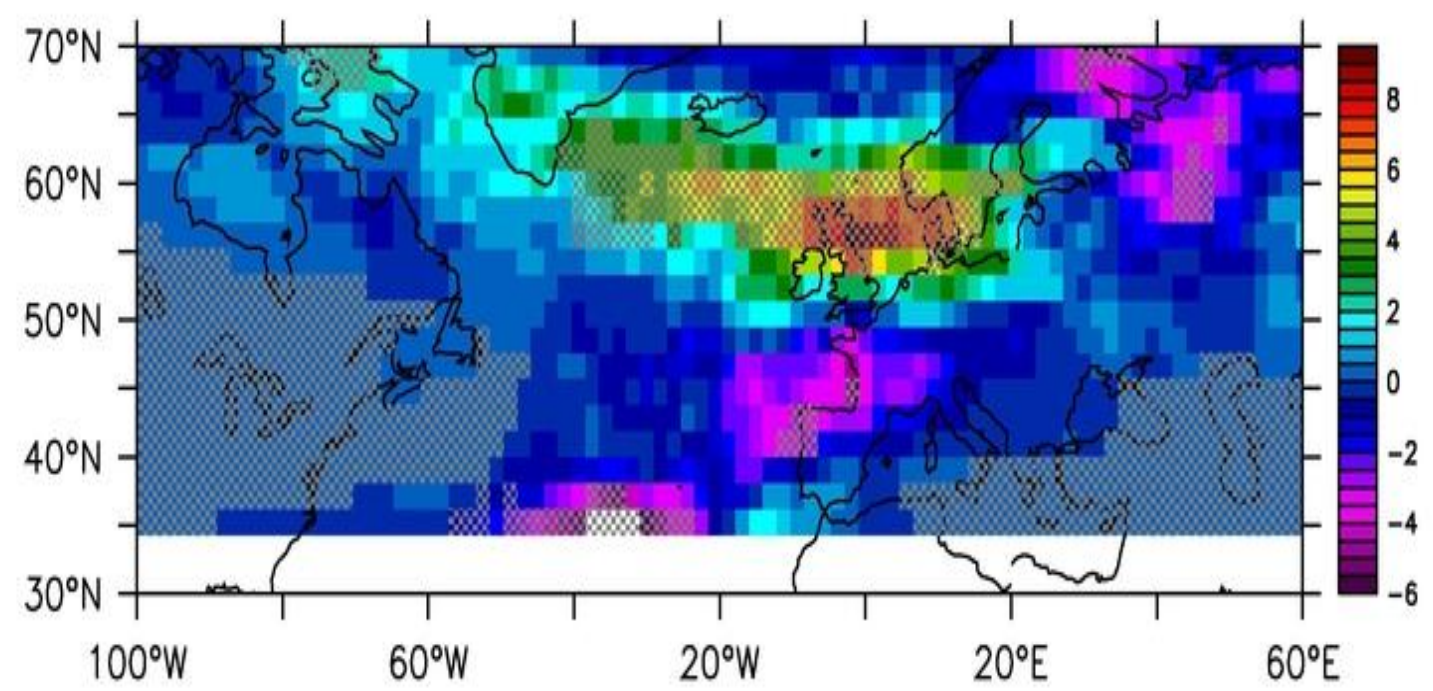

Figure 4c. Composite of blocking days based on positive minus negative AMO events stronger than one standard deviation. Stippling denotes significance of difference at $95 \%$ level.

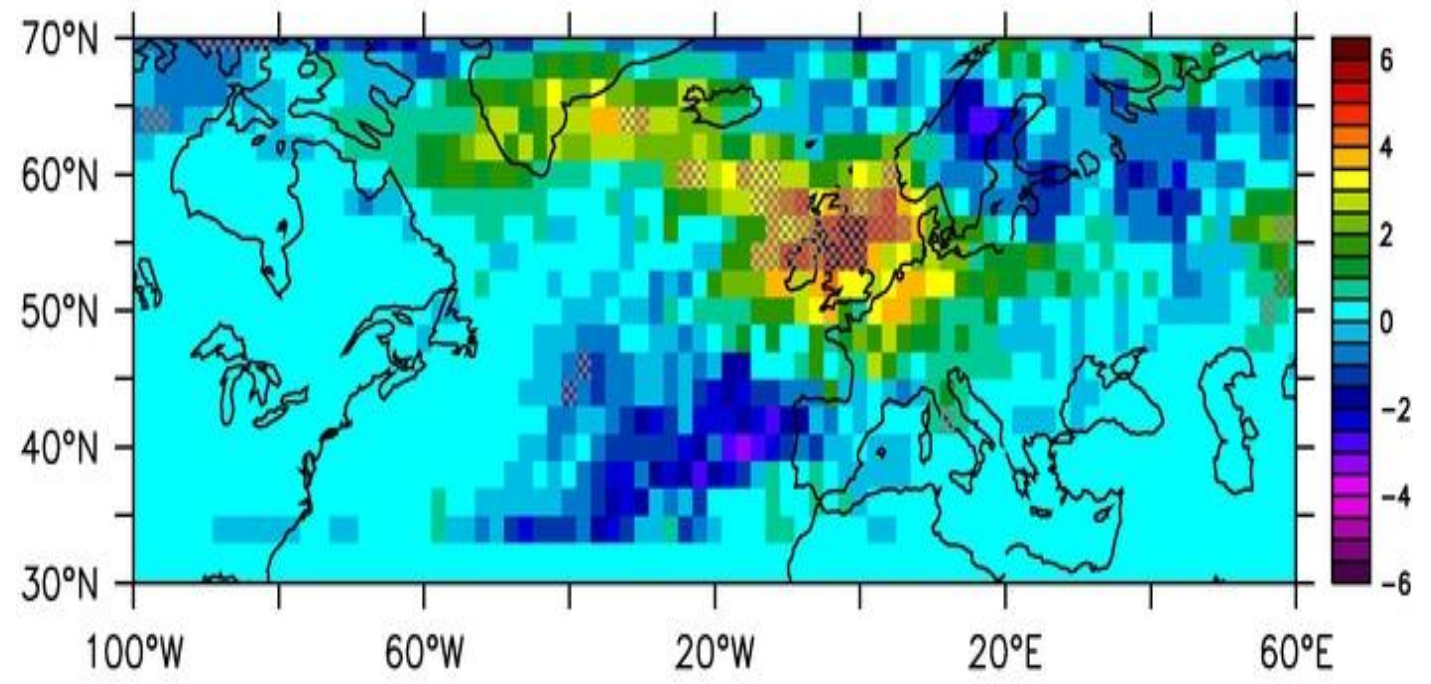

Figure 4d. Warm minus cold years (1939-1964 minus 1900-1929 as defined in (21)) difference in blocking days. Stippling denotes significance of difference at 95\% level assuming 58 degrees of freedom. 


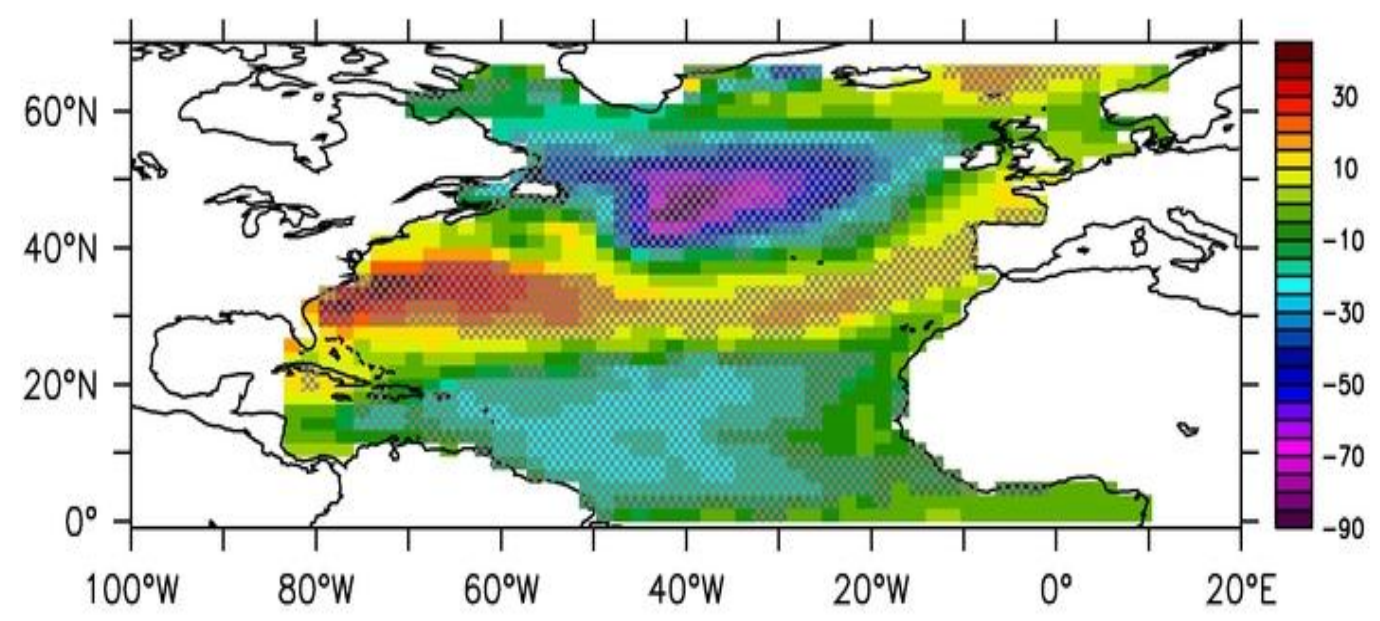

Figure 5 Composite of turbulent heat flux (positive upward) based on negative minus positive curl PC2 events stronger than one standard deviation. Stippling denotes significance of difference at $95 \%$ level. 


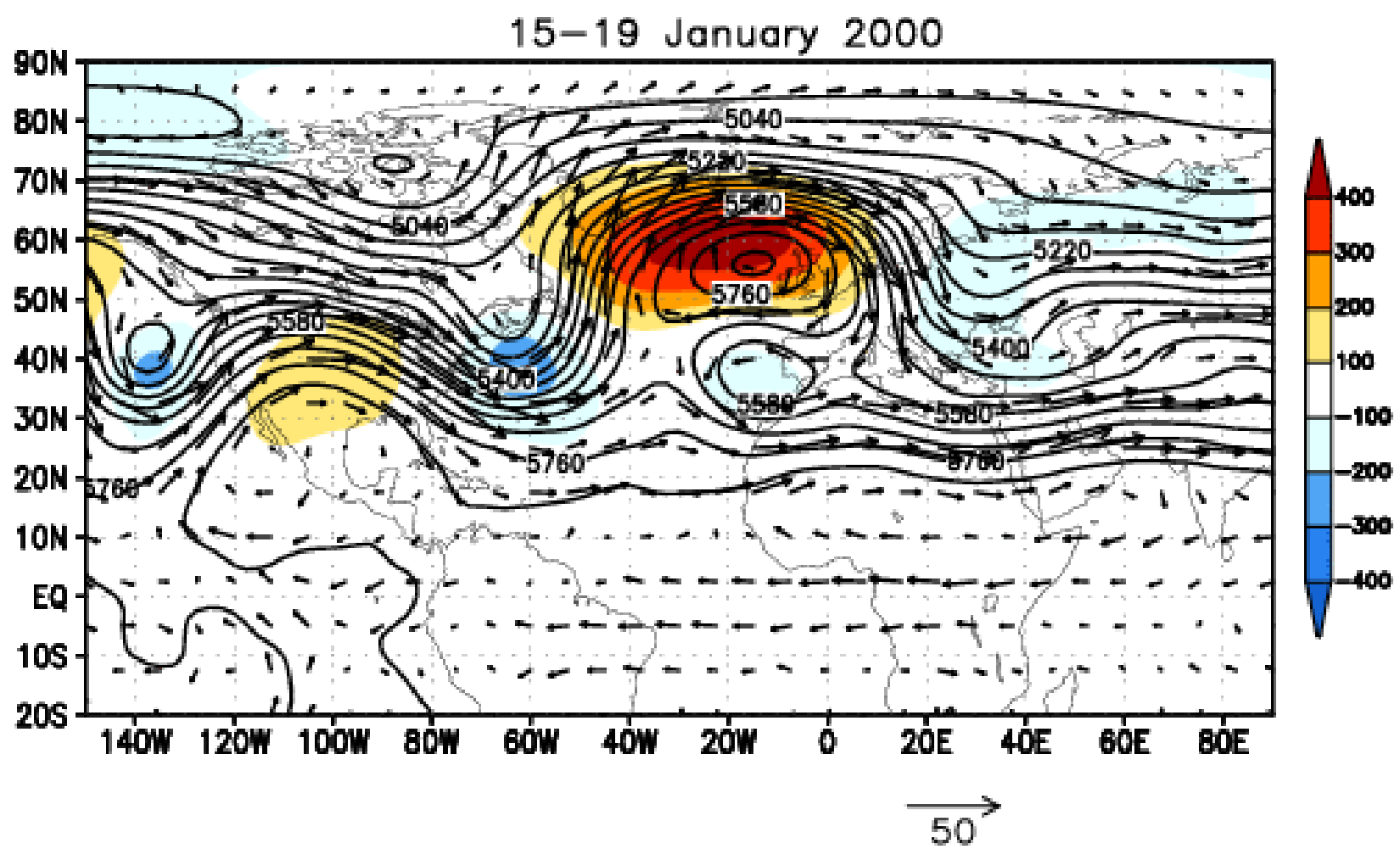

Figure S1 Example of Atlantic blocking from NCEP analysis. 500hPa geopotential height (contours; m), and its anomalies (color; m). From http://www.cpc.ncep.noaa.gov/products/precip/CWlink/blocking/background/atlantic_case.shtml 


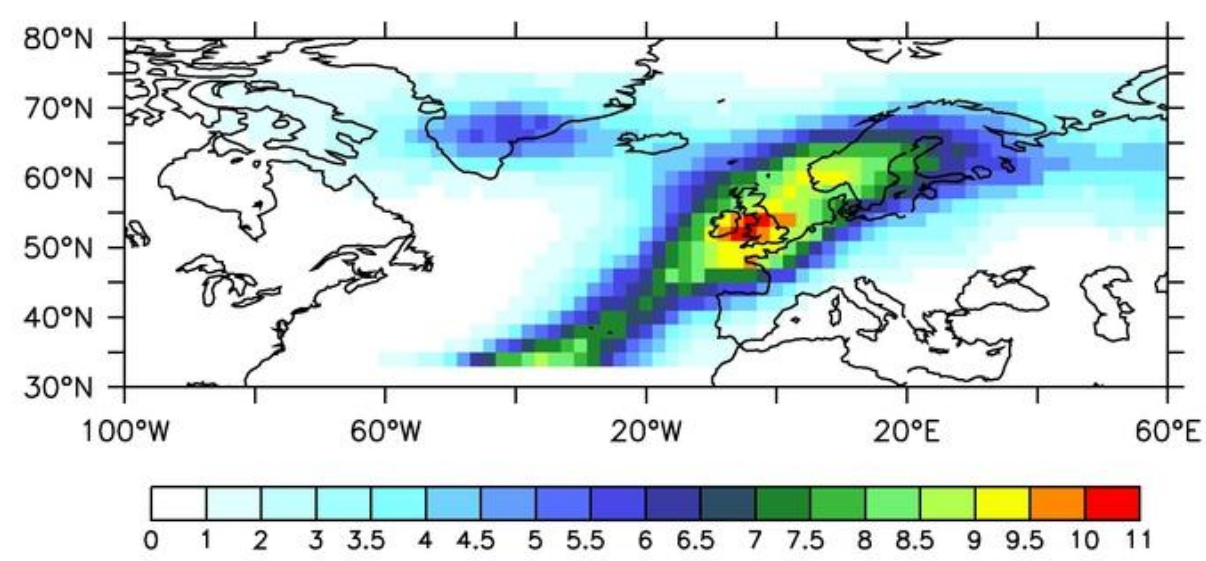

Figure S2 Climatological number of blocking days in December-March season. 

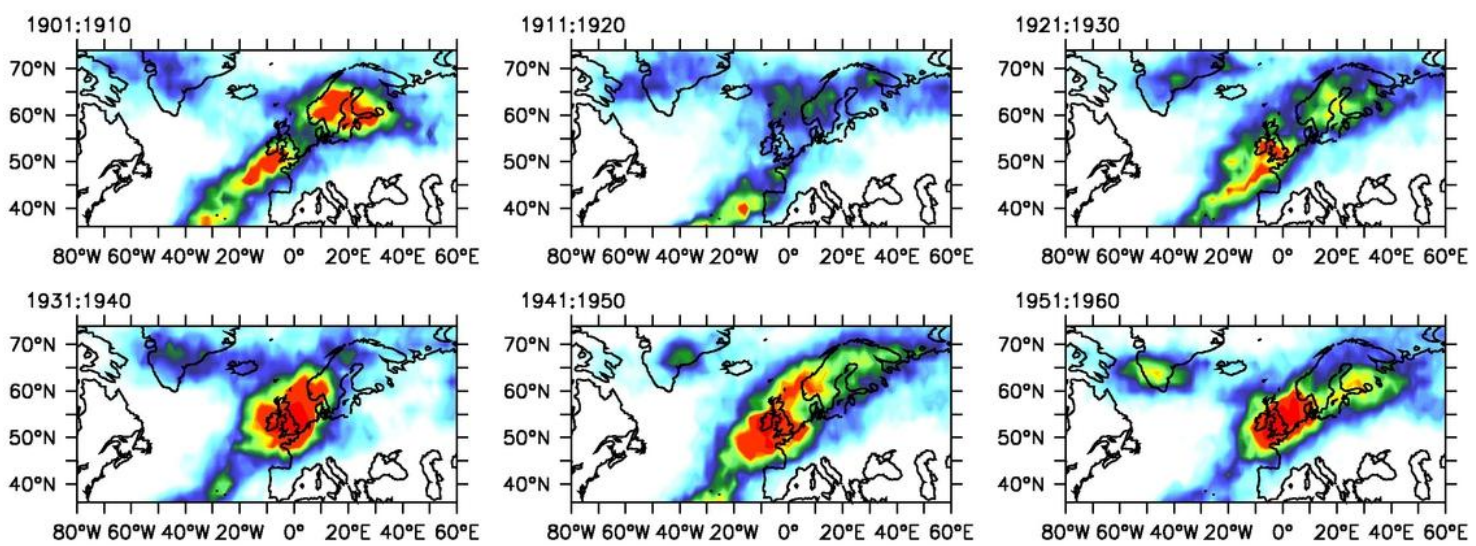

1941:1950
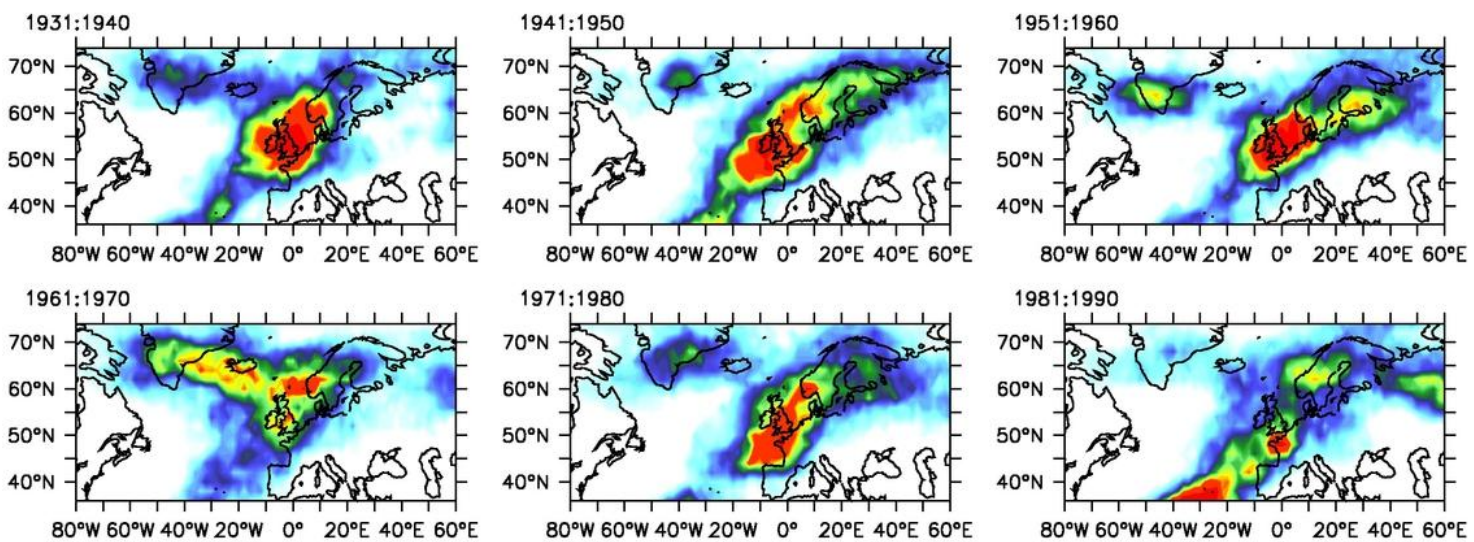

1971:1980
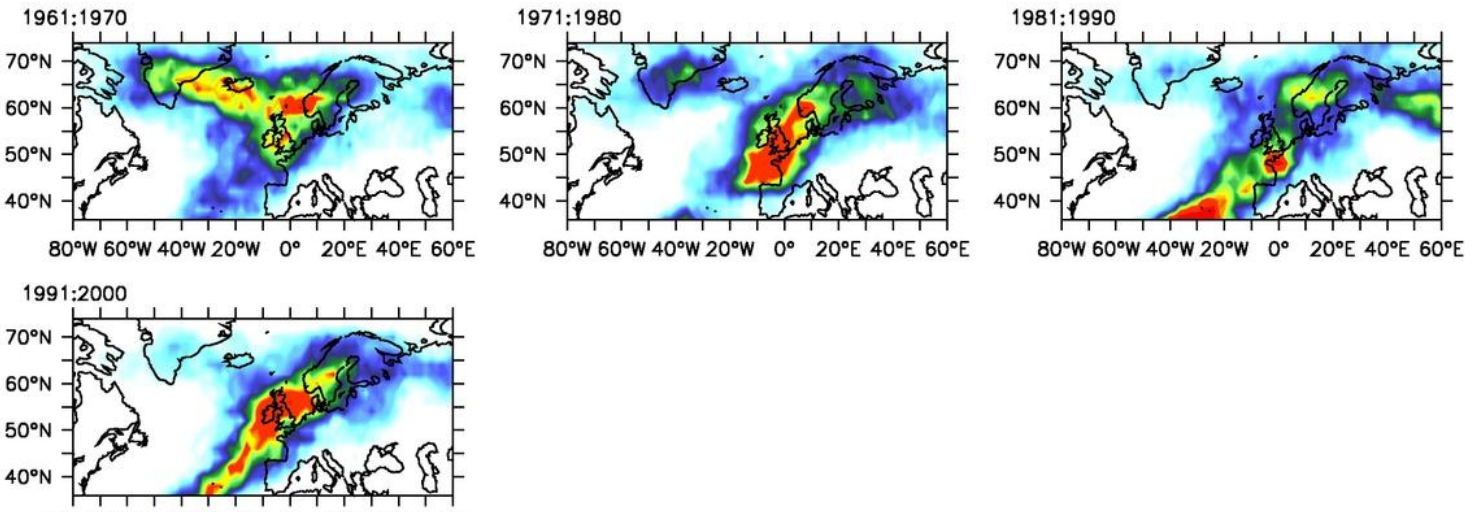

$80^{\circ} \mathrm{W} 60^{\circ} \mathrm{W} 40^{\circ} \mathrm{W} 20^{\circ} \mathrm{W} \quad 0^{\circ} \quad 20^{\circ} \mathrm{E} \quad 40^{\circ} \mathrm{E} 60^{\circ} \mathrm{E}$

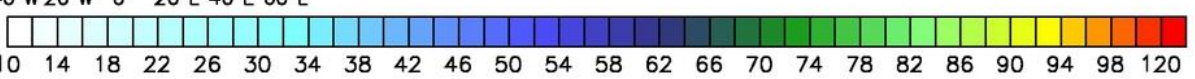

Figure S3 Decadal blocking days from the $20^{\text {th }}$ century reanalysis. 